\title{
In Memoriam Lynne Rudder Baker
}

Social Ontology owes much to Lynne Rudder Baker. We, the editors of the Journal of Social Ontology, like to think that it is on this rapidly evolving domain of research that the various lines of philosophical research of her impressive life's work converge. Together, her Critique of Physicalism (1987), her distinctive view of mental attitudes (1995), her extremely influential position in the metaphysics of constitution and her account of personhood (2000) as well her metaphysics of everyday objects (2007) combine to a clear and distinctive account of how social phenomena exist - genuinely and nonredundantly. Following an earlier contribution in the first volume of JSO in 2015, Baker submitted the following paper before her death in December 2017. With the permission of Tom Baker, we proudly include her contribution in this issue.

Her clear and convincing voice will be missed.

The Editors

\section{Lynne Rudder Baker ${ }^{\dagger}$}

\section{Just What is Social Ontology?}

https://doi.org/10.1515/jso-2019-2001

Abstract: Construing ontology as an inventory of what genuinely and nonredundantly exists, this paper investigates two questions: (i) Do all - or any social phenomena belong in ontology? and (ii) What difference does it make what is, and is not, in ontology? First, I consider John Searle's account of social ontology, and make two startling discoveries: Searle's theory of social reality conflicts with his ontological conditions of adequacy; and although ontology concerns existence, Searle's theory of social reality is wholly epistemic. Then, I offer my own view of social reality, on which social phenomena are ontologically significant. Since ontology concerns what genuinely and nonredundantly exists, anyone interested in what there is ought to care about ontology.

Keywords: Ontology; Social phenomena; Searle; Social individuals; Social complexes.

Lynne Rudder Baker, University of Massachusetts Armherst, Department of Philosophy, Amherst, MA 01003, USA

¿ Open Access. ( 2019, Lynne Rudder Baker, published by De Gruyter. (c) BY under the Creative Commons Attribution 4.0 Public License. 


\section{Introduction}

Social ontology is a budding branch of philosophy, but there has been little consideration of what exactly social ontology is. ${ }^{1}$ Social phenomena include financial transactions, cocktail parties, two people walking together, athletic teams, and legislatures, among countless other things - a "motley crew," as Margaret Gilbert has called them (1989, p. 441). Construing ontology as an inventory of what genuinely and nonredundantly exists, do all - or any - social phenomena belong in ontology? And why should anyone care about what is, and is not, in ontology at all?

Before answering these questions by offering my own account of social ontology, I want to discuss a different but well-known account - John Searle's - about which I think I've made a startling discovery. Searle has at least three articles with the words "Social Ontology" in the titles, and he considers his project an attempt to "explain the fundamental nature and mode of existence - what philosophers call the essence and ontology - of human social institutional reality" (Searle 2010, p. ix). The surprise is that the overall ontology to which Searle is committed excludes his theory of social reality.

\section{John Searle on "Social Ontology"}

Searle's question, as he has posed it, is, "What is the ontology of social reality?" (Searle 2007, p. 4) As we shall see, there is a real puzzle about Searle's use of the word "ontology."2 Searle's view is complex: social and institutional reality depends on what he calls "status functions," that is, functions that human beings confer on physical objects and people by a type of speech act; these functions, in turn, carry deontic powers - rights, duties, obligations, etc. (Searle 2010, p. 7-9).

Although I am not going to summarize Searle's view here, the basic puzzle is this: On the one hand, Searle says, [The world] "entirely consists of physical particles in fields of force," and hence is independent of minds (Searle 1995, p. 7). But on the other hand, he says, "social reality exists only because we think it exists;" it is created by us (Searle 2006, p. 13, 2010, p. 11). Searle needs to show,

1 In June 2015, Lynne Rudder Baker presented this paper at the conference "Social Complexes: Parts and Wholes II: Perspectives from Ethics, Metaphysics and Philosophy of Action” held at the University of Gothenburg, Sweden [Footnote by the editors].

2 Searle calls himself an "external realist" (Searle 1995, p. 153-154). He notes that realism is a theory of ontology, and thus is not a theory of truth nor an epistemic theory. Realism is "the view that there is a way that things are that is logically independent of all human representations" (Searle 1995, p. 155). I shall argue that his view of ontology has no place for social ontology, as Searle characterizes it. 
then, how an entirely physical ontology can include social phenomena that exist only because we think that they exist.

In Making the Social World, Searle lays down two conditions of adequacy for a theory of social reality. First, "we must not allow ourselves to postulate two worlds or three worlds or anything of the sort. We live in exactly one world" (Searle 2010, p. 3), and that is "the world described by physics and chemistry" (Searle 2007, p. 4). ${ }^{3}$ The second condition is like unto the first: the theory of social reality must show how non-basic facts (namely, social facts) are derived from basic facts (namely, facts given by the physical sciences). Indeed, he says that the "basic requirement of our enterprise" is to show how "all the phenomena that we discuss - money, universities, cocktail parties, and income tax are...derived from and dependent on the basic facts" (Searle 2010, p. 4).

The term "derive" here is ambiguous. It may be used in such a way that what is derivative does not add anything to the reality already implicit in what it was derived from, or it may be used in such a way that what is derivative does add to the reality that was already there in what it was derived from. Compare logic, where a deductive inference is "explicative," in that it adds nothing to what was already implicitly in the premises, and an inductive inference is "ampliative," in that it adds to what was implicitly in the premises.

Either way that we disambiguate the term "derive" leads to a dilemma for Searle. On the one hand, if social reality does not add anything new to what was already there, then social phenomena have no place in ontology; locating social phenomena in the ontology of such a world would be like adding heat to an ontology that already contains molecular motion. Doing so would just be redundant. An ontology of physical particles would be complete. But on the other hand, if social phenomena really do add something new to what was already there, then locating social phenomena in ontology would imperil Searle's physicalism: the world would not "entirely consist of physical particles." Either way, Searle cannot have both social ontology and a physicalist view of ontology in general.

To put the problem differently, Searle says, "there are at least two different senses of the objective/subjective distinction: an epistemic sense and an ontological sense” (Searle 2010, p. 18). Searle explains, “ontological objectivity and subjectivity have to do with the mode of existence of entities. Epistemic objectivity and subjectivity have to do with the epistemic status of claims" (Searle 2010, p. 18). In Making the Social World, he formulates the question at issue like this: "How can there be

3 A more complete expression of the idea is this: "We know independently that the world consists entirely of physical particles in fields of force (or whatever the ultimately correct physics tells us are the final building blocks of matter) and that these physical are organized into systems and that soe of the carbon-based systems have evolved over a period of about 5 billion years into a very large number of animal and plant species, among which we humans are one of the species capable of consciousness and intentionality" (Searle 2006, p. 13). 
an epistemically objective set of statements about a reality which is ontologically subjective?" His answer, in brief, is that the social world is ontologically subjective in that its existence depends on the attitudes of others, but it is epistemically objective, in that statements about social phenomena are not just matters of opinion, but are knowable independently of the attitudes of others (Searle 2010, p. 18).

Since ontology concerns existence, not knowledge (Searle 2010, p. 18), the epistemic objectivity of the social world has no bearing on ontology. On Searle's view, what makes something social is an epistemic matter of our conferring a status on physical phenomena. A cocktail party is a gathering of people that we count as a cocktail party. So, when Searle says that the social world is "ontologically subjective," the word “ontologically” is just a façon de parler; in light of Searle's general ontology, what is ontologically subjective has only epistemic import, no ontological significance at all. Otherwise, ontology would not conform to physicalism. Hence, given Searle's conditions of adequacy for a theory of social reality - a theory of social phenomena in a world that is entirely physical - there is logically no place for social phenomena in ontology. Putting social phenomena in ontology would either render the ontology redundant, or would abrogate Searle’s physicalism.

\section{A Different Approach to Social Phenomena}

On my view, social phenomena do belong in ontology. Although I agree with Searle that we human beings make an essential contribution to the existence of social reality, a crucial difference between Searle and me is that I am a pluralist, not a physicalist. I do not endorse Searle's physicalism, the view that "all that exists in the world are physical particles with their properties and relations" (Searle 1984, p. 26-27). Let me begin with my overall view of ontology.

\section{General Ontology}

Ontology, as I mentioned, is an inventory of reality, of what genuinely exists without redundancy - for example, what objects, properties and kinds there really are. ${ }^{4}$ By "reality," I mean to include everything required to make intelligible what we perceive and interact with and what survives our inquiries. ${ }^{5}$ Since not all

4 In the Stanford Encyclopedia of Philosophy, Thomas Hofweber identifies two parts to overall ontology: "what there is, what exists, what is the stuff that reality is made of," and "what the most general features and relations of these are" (Hofweber 2014). Note that neither of these parts is epistemic. 5 Phlogiston, for example, does not belong in ontology since appeal to such a thing did not survive our investigations. 
the objects, properties and kinds that exist now have always existed, we can only construct time-indexed ontology - ontology at a time. For something to be in the ontology at $\mathrm{t}$, it must be irreducible to anything else and ineliminable at t. Total ontology, to which we have no access, includes what genuinely exists at any time (including the future).

There are three important features of my conception of the natural world: (i) Primary kinds, (ii) the relation of constitution, and (iii) the existence of intention-dependent phenomena. First, primary kinds: For any x, we can ask, what most fundamentally is $\mathrm{x}$ ? The answer is what I call x's "primary kind." Everything that genuinely exists has a primary-kind property - being a horse, being a table, being a passport, being a person. The primary-kind property tells what the thing basically is. It has its primary-kind property essentially; an object could not exist without its primary-kind property. Moreover, primary-kind properties are neither eliminable at t nor reducible and hence belong in ontology at $t$, as do the objects of those primary kinds (such as a horse or a table).

Second, the relation of constitution: Entities are unified by a relation that I call “constitution.” As I have argued at length elsewhere (Baker 2000, 2007, 2013), constitution is a time-indexed, contingent relation of unity between items of different primary kinds - e.g. between a person and her body at $t$, between a dollar bill and a piece of paper at $t$, between a baseball team and its players at $t$. When, say, a piece of sheepskin is in certain circumstances (diploma-favorable circumstances), it comes to constitute a new object, a diploma. Constitution is thus a vehicle of ontological novelty. If $x$ constitutes $y$ at $t$, then y's primary-kind property confers on y causal powers that the constituter, $x$, would not have if it had not constituted anything. ${ }^{6}$ So, constitution is not identity. Nor is constitution a part-whole relation. If $\mathrm{x}$ constitutes $\mathrm{y}$ at $\mathrm{t}$, then $\mathrm{x}$ cannot be a proper part of $\mathrm{y}$ (since $\mathrm{y}$ is not identical to $\mathrm{x}+$ other part); and $\mathrm{x}$ cannot be an improper part of $\mathrm{y}$ (since $\mathrm{x}$ and $\mathrm{y}$ are not identical).

Incidentally, I believe that every concrete object in the natural world is ultimately constituted by physical particles, but that does not imply that the world "entirely consists of physical particles." As I mentioned, constitution is a vehicle of novelty: it adds new kinds of things to ontology.

Third, intention-dependent phenomena: a significant feature of our world is that it is populated by things - such as pianos, pacemakers, and paychecks whose existence ontologically depends on the existence of persons with propositional attitudes. I call any object that could not exist in a world lacking beings with beliefs, desires and intentions an "intention-dependent object," or an "ID

6 More precisely, y's primary kind confers many causal powers nonderivatively on y. An entity $\mathrm{x}$ has a property nonderivatively if the exemplification of the property by $\mathrm{x}$ does not depend on what $\mathrm{x}$ constitutes or what constitutes $\mathrm{x}$. 
object." ID objects that we are familiar with include kitchen utensils, precision instruments, credit cards and so on. ID properties are properties that cannot be instantiated in a world without beings with beliefs, desires and intentions; and similarly, for ID events and ID phenomena generally. ${ }^{8}$

Underlying the idea of ID phenomena is a distinction between minddependence and mind-independence. Mind-dependent phenomena ontologically cannot exist or occur in a world without minded entities who have an array of attitudes (like believing, desiring, intending); mind-independent phenomena can exist or occur in a world that has no such minded entities. Social phenomena of all sorts are ID phenomena and thus mind dependent.

Mind-dependent objects are not necessarily subjective. A baseball diamond is an ID object but is not subjective, either ontologically or epistemically. Thus, my mind-independent/mind-dependent distinction is not equivalent either to Searle's ontological objective/subjective distinction or to his epistemic objective/ subjective distinction. ${ }^{9}$ A crucial difference between physicalists and me is that on my view, mind-dependent phenomena may be just as genuine or as "real" as mindindependent phenomena. Many (perhaps all) physicalists take mind-independent phenomena to be ontologically superior to mind-dependent phenomena.

I disagree: Temporally prior, yes; but we should not confuse temporal with ontological priority. An entity $\mathrm{x}$ is ontologically prior to $\mathrm{y}$ only if $\mathrm{x}$ has greater ontological significance than $y$. Mind-independence does not confer ontological significance. (This seems obvious if you think of the time right after the Big Bang: the entities and properties that existed then presumably were mind-independent, but not more ontologically significant than artworks and artefacts that exist today. Artefacts - say, robots-could not exist in a world without minds, but they

7 Gary Matthews suggested the term "ID phenomena" for phenomena whose occurrence or existence depends on there being entities with propositional attitudes.

8 A large variety of phenomena are ID phenomena. For example, the event of writing a check is an ID event, because there would be no such thing as writing a check in a world lacking the social and economic conventions that presuppose that people have beliefs, desires and intentions. (Writing a check is a fundamentally different kind of phenomenon from moving one's hand, and still more different from one's hand's moving.) Most human activities are ID phenomena - both individual (getting a job, going out to dinner, designing a house) and collective (manufacturing automobiles, changing the government, etc.). They could not exist or occur in a world without beliefs, desires, and intentions.

9 Indeed, I believe that Searle's notion of ontological subjectivity is confused. Sometimes he says that what is ontologically subjective "exist[s] only as experienced by human or animal subjects". His examples are tickles and pains. But at other times, he says that "observer-relativity implies ontological subjectivity" (Searle 2006, p. 15), and he takes screwdrivers to be observer-relative since they depend on the attitudes of the makers and users (Searle 1995, p. 10). Hence, he must take screwdrivers to be ontologically subjective. But screwdrivers (like other social (ID) objects) exist when they are not being experienced. 
have no less ontological significance than the atoms and gases that existed in the first minute after the Big Bang. $)^{10}$

To sum up: General ontology concerns nonredundant reality - what genuinely exists, (at a time), what is irreducible and ineliminable then. The universal relation that lower-level entities bear to the entities that they make up is constitution - a relation of unity that is not identity. Every constituted thing is of some primary kind or other, where a primary-kind property identifies the essence of the thing, what it is most fundamentally. The fact that some primary kinds (artefacts, artworks) are intention-dependent in no way diminishes their ontological status.

\section{Social Ontology}

General ontology has a number of subfields, domain-specific or regional ontologies (Elder-Vass 2010, p. 68). Social ontology is such a domain-specific subfield, which should include the basic entities, properties and kinds studied by the social sciences. ${ }^{11}$ There are two kinds of social entities: social individuals and social complexes or collectives.

I'll say that a property is social if and only if its instantiation requires that there exist communities of creatures with attitudes (like believing. desiring, and intending). I have no theory of communities except to say broadly that they are pluralities of individuals considered collectively who have something in common - perhaps intentional (e.g. by sharing the same aim or goal), but perhaps not (e.g. by being recruits in an army).

A word about social individuals before moving to our main topic, social complexes. Social individuals that have social primary-kind properties belong in the social ontology. Human persons are social individuals who have social primarykind properties - namely, first-person perspectives - in virtue of which they are persons. Although many nonhuman animals have rudimentary first-person

10 My view here is somewhat idiosyncratic. Most philosophers who recognize ontological levels privilege the lower levels (e.g. the level of physical particles) over the higher levels (e.g. the level of complex machines, or organisms). I think that (nonreductive) emergence gives rise to the opposite assessment. Indeed, in my opinion, the more items that are "fundamental" (irreducible and ineliminable), the richer the reality. My approach is the opposite of Jonathan Schaffer's in "What Not to Multiply Without Necessity." His meta ontology fits exactly his Spinozistic ontology that there is only one substance, and it is fundamental. I suppose that my meta-ontological opinion fits my massively pluralistic ontology.

11 More specifically, social ontology includes irreducible and ineliminable (at a time) social properties (i.e. properties whose exemplifications require the existence of social communities), entities of social primary kinds (i.e. entities whose primary kind properties are social properties) and social primary kinds (i.e. kinds whose existence requires the existence of social communities). 
perspectives (i.e. consciousness and intentionality), only persons have robust first-person perspectives made possible by complex natural language. The evolution of human persons parallels the evolution of natural language, and natural language requires the existence of linguistic communities, which are paradigms of social communities. I've spelled this out elsewhere (in Baker 2013, p. 126-143, 2015). Human persons are in the ontology in virtue of having first-person perspectives as their primary-kind property.

The focus here is not on social individuals, but social complexes, for example, institutions - legislatures, universities, teams, armies, nations, and so on. These complexes are constituted by aggregates of legislators, provosts, professors, players, soldiers, citizens, etc. On my view, the aggregate of individuals who make up a social complex at $t$ constitutes it at that time. All constituents of a social complex have at least a rudimentary first-person perspective - i.e. consciousness and intentionality.

A social complex may be constituted by different aggregates of individuals at different times. The baseball team gets a new pitcher; the first-baseman is traded to another team. But at each moment that the baseball team exists, there is an aggregate of individuals that constitutes the team at that time.

Constitution is a complicated relation that not only requires a constituter (whether an individual or an aggregate), but also requires that the constituter be in certain circumstances, different circumstances for different kinds of social complex. Let "S" stand in for a social entity (individual or complex), I'll use the term "S-favorable circumstances" for the different kinds of circumstances in which a social entity $\mathrm{S}$ comes to be constituted. The $\mathrm{S}$-favorable circumstances are analogous to Searle's constitutive rules (or rather to the rules' antecedents if the rules are expressed as conditionals). Here are some examples:

When what is constituted is a social individual, its immediate constituter is a single individual object: For example, a driver's license is constituted by a piece of plastic; a piece of plastic constitutes a driver's license only in driver's-licensefavorable circumstances that include being issued by the Department of Motor Vehicles, having printed on it a picture of, and information about, the driver. (I think that Searle's supposition that you typically start with a physical thing and then declare it to have a status function is too simple; the piece of plastic itself is brought into existence in order to constitute a driver's license, and driver's licenses are interwoven into a whole way of life.) But when what is constituted is a social complex, its constituter at $t$ is an aggregate.

The electorate is constituted at t by the aggregate of eligible voters at $t$. The differences among different social complexes - say, a baseball team and a nation-state show up in the different S-favorable circumstances for aggregates to constitute them. My point here is that there are different $S$-favorable circumstances for citizenship in the US than for membership on a baseball team. All the differences in social entities 
(individual or complex), I believe, can be accommodated in this way, by differences in S-favorable circumstances for the constitution of different social entities. ${ }^{12}$

Institutions may be of social primary kinds, and hence belong in ontology. Like other primary-kind properties, social primary-kind properties are irreducible and (at a time) ineliminable; they also have the following two features: (i) they can be instantiated only by social entities, and (ii) their instantiation requires the existence of social communities - think of the properties of being married, of being employed, of being elected to office, of being an owner of property. In these cases, social communities show up in the S-favorable circumstances (e.g. laws and conventions conferring rights and duties) of marriage, employment, election, and property-ownership. Different institutions are distinguished from one another by having different S-favorable circumstances.

For example, a university, I think, has a primary-kind property of engaging in advanced teaching and research. It is constituted by fluctuating aggregates of students, professors, administrators and so on, but it cannot be reduced to individuals in the aggregate that constitute it at any time. The S-favorable circumstances in which an aggregate constitutes a university include qualifying for different roles - administrators, professors at various ranks, counselors, staff, students. Social complexes, as entities, have causal powers that the individuals who make them up do not have, either singly or collectively. For example, a university confers degrees. Whoever hands you the diploma does not confer the degree; he or she only acts as the authorized representative of the university. The degree is conferred by the university. [Other examples: In the US, Congress declares war, not members of Congress or of the Administration. Armies have battle plans, not individual soldiers.]

Consider a different example: marriage is an irreducible social and legal institution; so, marriage and its primary-kind property, being married, belong in the ontology. The S-favorable (marriage-favorable) circumstances for the kind marriage include having a willing partner, exchanging vows administered by an official who signs a license. The institution of marriage itself could change with a change in marriage-favorable circumstances.

The institution of marriage is constituted at $t$ by all those who are married at t. However, just as an army is irreducible to aggregates of soldiers, so too is marriage irreducible to aggregates of married people. Indeed, I reject methodological individualism: the institution of marriage is something over and above

12 For example, consider the S-favorable circumstances for aggregates to constitute the United States, a nation-state. An infant born in the US of parents who are US citizens, is automatically a citizen of the US. When she is born, the aggregate of people who constitute the US citizenry is increased by one. Although she may renounce her citizenship when she grows up, she does not choose to be a citizen of the US in the first place. Another way to complicate matters, there are different US-citizenry-favorable circumstances for naturalized citizens. So, the S-favorable circumstances that aggregates fulfill to be citizens of the U.S. are disjunctive. 
the married individuals. We can see this by noting that we can infer very little about the institution of marriage at a given time from the aggregate of individuals who are married at that time. Moreover, the institution confers causal powers on married people - for example, married people can file joint tax returns (in the US); unmarried people cannot.

Marriage is an ID institution: in a world without entities with attitudes, there could be no marriage. Not only must the participants in a marriage ceremony have certain attitudes (e.g. they must believe that they know what they are doing), but also the S-favorable circumstances for marriage - e.g. getting a qualified person to perform marriages, implementing the apparatus for issuing marriage licenses - require certain attitudes. Intertwining and integrated attitudes form complicated networks for many social institutions.

Suppose that people stopped getting married. Sooner or later there would be no married couples to constitute the institution of marriage. But marriage may nevertheless remain on the books. Would the institution just disappear? I think not - at least not right away. ${ }^{13}$ However, the institution of marriage would disappear altogether if the marriage-favorable circumstances could not be satisfied - e.g. if people stopped qualifying to perform marriages, or if the apparatus for issuing marriage licenses was dismantled. In that case, marriage would go the way of primogeniture.

Let me summarize my view of social ontology: Taking "social community" as a primitive, we can characterize a social property as a property the instantiation of which requires the existence of a social community. Typically, for human beings that means a linguistic community. Social ontology at a time t contains all the instantiated social properties that are irreducible and ineliminable at that time. This will comprise the social properties that are primary kinds that are instantiated at $t$ and the entities (individual or complex) that have those social properties as their primary-kind properties.

Someone might mount an ad hominem objection against me. After all, I think that social reality depends on people's attitudes, and I think that that is no bar to social ontology. How can I complain when Searle does the same thing?

13 If marriage remained "on the books" - if the marriage-favorable circumstances were still accepted although no one later fulfilled them - marriage would become an empty institution. Since constitution is time-indexed, there may be a time during which the property of being married would be unexemplified, but still could be exemplified Perhaps the institution of incometax is a better illustration of how an institution can become empty, and then later be revived. Suppose that one year, no on had enough income to have to pay a tax. For that year, the institution of income-tax would be empty.

When an institution is empty (and has no exemplars of its primary-kind property), but the institution-favorable circumstances remain intact (accepted, "on the books"), it could be revived. In the case of the income-tax, when people started having more income, the income tax-favorable circumstances would be satisfied. And there would again be an aggregate of income-tax-payers. 
Well, Searle does not do the same thing. There are at least three important differences between Searle and me. First, Searle is a physicalist (Searle says that "we know independently that the world consists entirely of physical particles in fields of force...." (Searle 2006, p. 13; my emphasis); I am a pluralist (there are innumerable primary kinds of things). Second, as I mentioned, although I have a mind-dependent/mind-independent distinction, I do not think that it marks any ontological divide or a basic division in reality. Third, I do not say, as Searle does, that there is a single source of all institutional reality, much less a single logicolinguistic operation: a Status Function Declaration (Searle 2010, p. 201). On my view, social entities are brought into existence by constitution in S-favorable circumstances, which may, but need not, include declarations. Some institutions may just evolve (e.g. cocktail parties). Although S-favorable circumstances include various intentions, there are numerous different kinds of S-favorable circumstances that make the constitution of different kinds of social realities possible. (Compare nation-states with baseball teams: there are different S-favorable circumstances for each.) Finally, let me note that I agree with Searle that language is required for institutions, and that we create social reality.

The fact that we create the social world does not call for any consternation or special explanation. Why shouldn't we persons - with our abilities, imaginations, and desires - be able to create genuinely new kinds of things? It is just a fact that we can - a fact on a continuum with the fact that beavers build dams. Artefacts are ontologically significant parts of reality that belong in ontology. And human contributions to ontology also include mind-dependent items like judicial systems, copyrights, and corporations. Since these mind-dependent items are irreducible and ineliminable at times and hence belong in ontology, there is no need to regard minddependent items as ontologically inferior to mind-independent items, and hence no consequent need to derive what is mind-dependent from what is mind-independent.

\section{Conclusion}

Ontology, I believe, comprises all the nonredundant and irreducible objects, properties and kinds required to make sense of the world. These include not only the commonsense items, but also the theoretical items, social and otherwise.

Social scientists may think that I have proceeded backward, that we should determine social ontology by starting with social-science theories and seeing what ontological commitments they make - as we do with natural scientists. Well, natural science differs from social science. The natural sciences are not constrained by the manifest image. However, social theories must accord with our commonsensical view of social phenomena to a significant degree. Social theories had better contain properties like living in poverty, being a bureaucracy, and 
participating in political elections that we all pre-theoretically recognize. Since ontology limits reality, ontology matters.

Back to the question with which we started: What difference does it make what is in the ontology and what is not? My answer is probably clear by now: Since ontology pertains to what there really is, anyone interested in what really there is, social scientist or not, ought to care about ontology.

Finally, just what is social ontology? Social ontology, on my view, is that part of a nonredundant inventory of reality that includes social individuals, properties and kinds. The relation of constitution, with different social S-favorable circumstances for different social entities, provides a schema for the whole "motley crew" that belong to social ontology.

Acknowledgements: The editorial board extends their gratitude to Anthonie Meijers for his help.

\section{Bibliography}

Baker, Lynne R. (1987): Saving Belief: A Critique of Physicalism. Princeton: Princeton University Press.

Baker, Lynne R. (1995): Explaining Attitudes: A Practical Approach to the Mind. Cambridge: Cambridge University Press.

Baker, Lynne R. (2000): Persons and Bodies: A Constitution View. Cambridge: Cambridge University Press.

Baker, Lynne R. (2007): The Metaphysics of Everyday Life: An Essay in Practical Realism. Cambridge: Cambridge University Press.

Baker, Lynne R. (2013): Naturalism and the First-Person Perspective. New York: Oxford University Press.

Baker, Lynne R. (2015): “Human Persons as Social Entities”. In: Journal of Social Ontology 1. No. 1, p. 77-87.

Elder-Vass, Dave (2010): The Causal Power of Social Structures. Cambridge: Cambridge University Press.

Gilbert, Margaret (1989): On Social Facts. Princeton: Princeton University Press.

Hofweber, Thomas (2014): "Logic and Ontology”, The Stanford Encyclopedia of Philosophy (Fall 2014 Edition), Edward N. Zalta (ed.), URL = <http://plato.stanford.edu/archives/fall2014/ entries/logic-ontology/>.

Searle, John R. (1984): Minds, Brains and Science. Cambridge, MA: Harvard University Press.

Searle, John R. (1995): The Construction of Social Reality. New York: The Free Press.

Searle, John R. (2006): “Social Ontology: Some Basic Principles”. In: Anthropological Theory 6. No. 1, p. 12-29.

Searle, John R. (2007): "Social Ontology and the Philosophy of Science”. In: Eric Margolis and Stephen Laurence (Eds.): Creations of the Mind. 3-17.

Searle, John R. (2010): Making the Social World: The Structure of Human Civilization. Oxford: Oxford University Press. 